\section{In-the-bag scleral suturing of intraocular lens in eyes with severe zonular dehiscence}

\begin{abstract}
Purpose To compare the degree of tilt and decentration of an intraocular lens (IOL), refractive status, and prediction error between eyes that underwent trans-scleral suturing of the IOL within the capsular bag (in-the-bag scleral suturing) and eyes that underwent scleral suturing outside of the bag (out-ofthe-bag scleral suturing) because of severe zonular dehiscence.
\end{abstract}

Patients and methods Thirty eyes that underwent in-the-bag scleral suturing of an IOL and 38 eyes that underwent out-of-the-bag scleral suturing were recruited sequentially. The tilt and decentration of the IOL, anterior chamber depth, manifest refractive spherical equivalent (MRSE), prediction error, and incidence of complications were examined. Results The mean tilt angle and the decentration length of the IOL of the in-thebag suturing group were significantly less than those of the out-of-the-bag suturing group $(P=0.0003$ in tilt and $P=0.0391$ in decentration), although the anterior chamber depth was similar. The mean MRSE and prediction error of the in-the-bag suturing group were less than those of the out-of-thebag suturing group $(P=0.0006$ in MRSE and $P=0.0034$ in error). The incidence of vitreous loss was less in the in-the-bag suturing group than in the out-of-the-bag suturing group (20\% vs $63.2 \%, P=0.0009$ ).

Conclusions The tilt and decentration of the IOL after in-the-bag scleral suturing are significantly less than those after out-of-thebag scleral suturing, which may lead to less MRSE and less prediction error. As the incidence of vitreous loss is less after in-thebag scleral suturing, in-the-bag suturing is advantageous for eyes of younger patients and of less complicated cases.
K Hayashi ${ }^{1}$, A Hirata $^{2}$ and $\mathrm{H} \mathrm{Hayashi}{ }^{3}$

Eye (2012) 26, 88-95; doi:10.1038/eye.2011.242; published online 23 September 2011

Keywords: cataract surgery; scleral suture fixation of intraocular lens; zonular dehiscence; intraocular lens displacement; refractive prediction error

\section{Introduction}

When performing cataract surgery for eyes with severe zonular dehiscence or lens subluxation, surgeons need to employ a surgical technique to fixate an intraocular lens (IOL) without adequate capsular support; ${ }^{1}$ these techniques include implantation of an open-loop anterior chamber IOL (AC-IOL); ${ }^{2-4}$ scleral suture fixation of a posterior chamber IOL (PC-IOL) ${ }^{5-7}$ iris suture fixation of a PC-IOL; and ${ }^{8-10}$ scleral fixation of a modified capsular tension ring with the IOL. ${ }^{11-14}$ However, after implantation of an AC-IOL, corneal endothelial damage or glaucoma escalation remain a concern in spite of refinement in design. ${ }^{2-4}$ In addition, after suturing of a PC-IOL to the sclera or iris, postoperative tilt and decentration due to inadequate haptic position is of particular concern. ${ }^{15-17}$ Previous studies have shown that marked tilt or decentration after scleral fixation occurs in approximately in $8-23 \%$ of cases. ${ }^{18-21}$ Our quantitative study has shown that the decentration or tilt of the IOL after scleral suturing is significantly greater than that after either in-the-bag or out-of-the-bag implantation of the IOL, which lead to a myopic shift. ${ }^{22}$ Furthermore, only one case report described by Kohnen et $a l^{23}$ showed quantitatively that the degree of decentration and tilt was relatively small after scleral fixation of the modified capsular tension ring.

Conventionally, intracapsular cataract extraction is performed for eyes with severe 
zonular dehiscence or lens subluxation. However, advances in surgical devices have increased our ability to preserve the capsular bag after cataract extraction-even in eyes with zonular dehiscence or lens subluxation. By using capsule stabilization devices, such as a flexible iris retractor, ${ }^{24,25}$ capsule expander, ${ }^{26}$ or capsular tension ring, ${ }^{27,28}$ phacoemulsification can be accomplished without worsening of zonular dehiscence. When the capsular bag is preserved, a PC-IOL can be sutured to the sclera or the iris within the bag, ${ }^{26}$ which we have called 'in-the-bag suturing of the IOL.' The surgical technique of in-the-bag scleral suturing is more difficult than that of scleral suturing outside of the lens capsule, termed 'outof-the-bag suturing', and in-the-bag suturing is not applicable for more serious cases. However, in-the-bag scleral suturing is assumed to be advantageous in terms of less IOL displacement, less prediction error, and less vitreous loss.

The objective of this study was to examine the degree of IOL tilt and decentration, anterior chamber depth, refractive states, prediction error, and the incidence of operative complications in eyes that underwent in-thebag scleral suturing of the IOL. In this study, eyes that underwent out-of-the-bag scleral suturing of the IOL served as controls.

\section{Patients and methods}

\section{Patients}

The medical records of all eyes that underwent scleral suturing of a posterior chamber IOL within the capsular bag (in-the-bag scleral suturing) and all eyes that underwent scleral suturing of an IOL outside of the capsular bag (out-of-the-bag scleral suturing) at the Hayashi Eye Hospital between July 2004 and November 2009 were sequentially screened for inclusion in this study. The inclusion criteria for the in-the-bag scleral suturing group were (1) eyes that underwent scleral suturing of the IOL within the capsular bag after phacoemulsification using capsule-supporting devices; (2) eyes with a minimal follow-up of 3 months; (3) first-operated eye if both eyes had undergone surgery; (4) eyes that had uneventful surgery; (5) eyes with no history of ocular inflammation; and (6) eyes in which a clear image was obtained by a Scheimpflug videophotography. Based on these criteria, 30 eyes were identified. The inclusion criteria for the out-of-the-bag scleral suturing group were (1) eyes that underwent scleral suturing of the IOL outside the capsular bag; (2) eyes with a minimal follow-up of 3 months; (3) first-operated eye; (4) eyes with no history of ocular inflammation; and (5) eyes in which a clear image was obtained by a Scheimpflug videophotography. Based on these criteria, 38 eyes were identified. Of the 38 eyes, the surgeon failed to maintain the capsular bag when performing phacoemulsification in 7 eyes; 9 eyes underwent intracapsular cataract extraction; and 15 eyes underwent extraction of a dislocated IOL. In the remaining seven eyes, the IOL was sutured because these eyes had either zonular dialysis or posterior capsule rupture. The lenses sutured were a single-piece polymethylmethacrylate (PMMA) IOL (CZ70BD; Alcon Laboratories, Fort Worth, TX, USA) or a hydrophobic acrylic IOL (VA65BB; HOYA, Tokyo, Japan). The CZ70BD had a $7.0 \mathrm{~mm}$ PMMA optic with modified C PMMA loops with eyelets. The VA65BB had a $6.5 \mathrm{~mm}$ acrylic optic with distended modified C PMMA loops. ${ }^{29}$ Of the 30 eyes that underwent in-the-bag scleral suturing of the IOL, two received the $C Z 70 B D$ and 28 received the VA65BB. Of the 38 eyes that underwent out-of-the-bag scleral suturing, 24 received the $\mathrm{CZ70BD}$ and 14 received the VA65BB. Informed consent was obtained from each patient included in this study. The Institutional Review Board approved the study protocol and all patients provided informed consent.

\section{Surgical procedures}

A single surgeon $(\mathrm{KH})$ performed all surgeries. For in-the-bag scleral suturing of the IOL, the surgeon employed the modified $a b$ interno method described by Mittelviefhaus and Wiek. ${ }^{7}$ First, a $3.0 \mathrm{~mm}$ scleral tunnel or a $2.5 \mathrm{~mm}$ clear corneal incision was made for phacoemulsification. After incision, a continuous capsulorrhexis measuring was accomplished by using a bent needle or an anterior capsule forceps under viscoelastic material (Viscoat, Alcon; or Healon 5, AMO, Santa Ana, CA, USA). After the capsulorrhexis, a flexible iris retractor or a capsule expander was hooked to the anterior capsule edge at four to five meridians (Figure 1). After hydrodissection, phacoemulsification of the nucleus and aspiration of the residual cortex were performed. Using a keratome, the wound was enlarged to $7.0 \mathrm{~mm}$ for implantation of the CZ70BD or to $4.1 \mathrm{~mm}$ for implantation of the VA65BB. The lens capsule was inflated with sodium hyaluronate 1\% (Healon; AMO), after which a fornix-based conjunctival flap was made temporally and nasally. Then, 9-0 polypropylene loopedsutures, with a long curved needle (PC-9; Alcon), were hitched to the haptic eyelets of the CZ70BD or to the distended haptics of the VA65BB. The PC-9 needles were pierced through the capsule from the ciliary sulcus to the sclera at the 3 and 9 o'clock meridians, approximately $1 \mathrm{~mm}$ posterior to the limbus. Next, the IOL was inserted into the capsular bag in an attempt to introduce the haptics to the ciliary sulcus. After another superficial bite was taken in the sclera, one arm of the suture was cut 


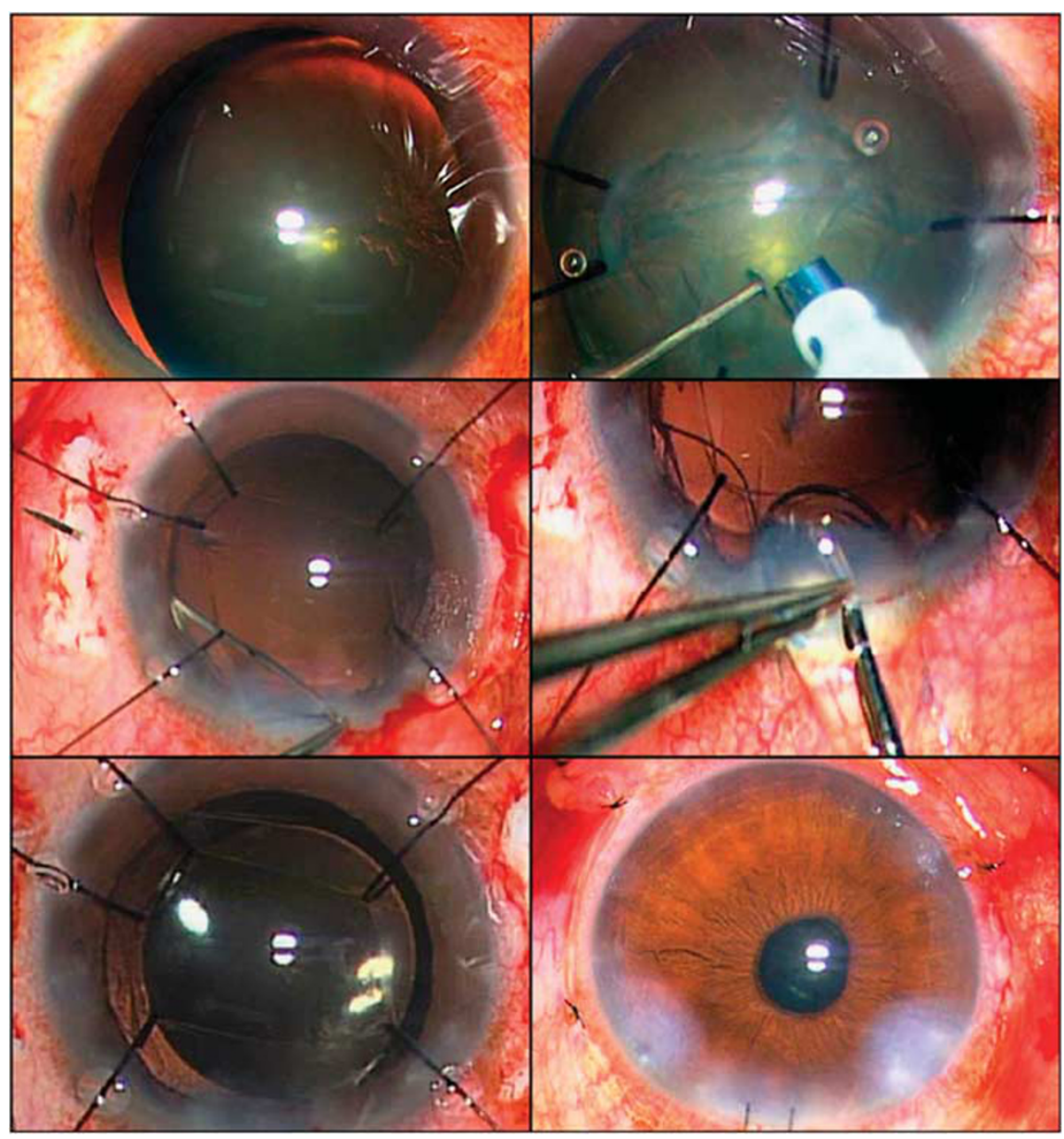

Figure 1 The surgical procedure of scleral suture fixation of a posterior chamber IOL within the capsular bag (in-the-bag scleral suturing). The lens is subluxated by zonular dialysis from the 12 to 6 o'clock meridians (top left). After a flexible iris retractor is hooked to the edge of the capsulorrhexis at four cross-meridians, phacoemulsification of the nucleus is performed (top right). After aspiration of the cortex, the capsular bag is preserved completely (middle left). The 9-0 polypropylene sutures with a long curved needle are hitched to the distended haptics of the acrylic IOL, and the needles are pierced through the lens capsule from the ciliary sulcus to the sclera at the 3 o'clock meridian (middle right). The folded acrylic IOL is inserted into the capsular bag in an attempt to introduce the haptics to the ciliary sulcus (bottom left). The trans-sclerally sutured IOL is then placed within the capsular bag (bottom right).

and then tied with the other arm of the suture on the bilateral side. When vitreous loss occurred, an anterior vitrectomy was performed using a vitreous cutter.

For out-of-the-bag scleral suturing of the IOL, the same modified ab interno method described above was employed. ${ }^{7}$ However, the procedures for extraction of cataract or dislocated IOL were different. For eyes with a luxated lens, the surgeon made a 10 to $11 \mathrm{~mm}$ superior limbal incision, and then extracted the lens with a looped cannula. After the wound was temporarily closed by 8-0 silk sutures, the prolapsed vitreous was removed by using a vitreous cutter. For eyes that underwent an exchange of a dislocated $\mathrm{IOL}_{1}^{30}$ the surgeon made superior $7.0 \mathrm{~mm}$ corneoscleral incisions for extraction of a PMMA IOL and $4.1 \mathrm{~mm}$ clear corneal incisions for extraction of a foldable IOL. The dislocated IOL was pulled up into the anterior chamber by means of a hook or IOL forceps. The PMMA IOL was then explanted through 7.0-mm corneoscleral wounds; the foldable IOL was cut using Vannas scissors; and the remaining part of the IOL was rotationally explanted through $4.1-\mathrm{mm}$ corneal wounds. For eyes with a posterior capsule rupture or a zonular dialysis, the original incision was enlarged according to the size of the lens remnants. The lens remnants were removed with a looped cannula or a vitreous cutter. When the vitreous was prolapsed, an anterior vitrectomy was conducted to preclude the vitreous incarceration.

\section{Main outcome measures}

Decentration length and tilt angle of the scleral sutured IOL, and anterior chamber depth, were measured by Scheimpflug videophotography (EAS-1000; NIDEK, 
Gamagori, Japan). The methods for calculating the decentration length and tilt angle with the EAS-1000 system have been described previously. ${ }^{22}$

Uncorrected and spectacle-corrected decimal visual acuity were recorded at each visit, and visual acuity was converted to a logarithm of minimal angle of resolution scale for statistical analysis. The objective refractive status and keratometric cylinder were measured by using an autorefracto-keratometer (KR-7100; Topcon, Tokyo, Japan). The refractive prediction error was determined as an absolute value of actual refraction from predicted (targeted) refraction. The pupillary diameter was examined by using the Colvard pupillometer (Oasis Medical, Glendora, CA, USA). The incidence of eyes that showed operative complications, including vitreous prolapse into the anterior chamber in which anterior vitrectomy was performed; temporary increase in intraocular pressure (IOP); glaucoma escalation; vitreous haemorrhage, cystoid macular edema; and retinal detachment, was examined. Transient IOP increase was defined as IOP higher than $21 \mathrm{~mm} \mathrm{Hg}$ within 2 weeks after surgery. Glaucoma escalation was defined as the development of new-onset glaucoma or the need for more aggressive control of glaucoma using one or more additional medications, or with surgical intervention.

\section{Statistical analysis}

The Mann-Whitney $U$-test was used for comparison of the degree of decentration and tilt of the IOL, anterior chamber depth, spherical equivalent, prediction error, and other continuous variables between the in-the-bag and the out-of-the-bag scleral suturing groups. Discrete variables were compared by using $\chi^{2}$-test or Fisher's exact probability test. Any differences showing a $P$-value less than 0.05 were considered statistically significant.

\section{Results}

The patient demographics of the two groups are shown in Table 1. No statistically significant differences were found in gender, ratio of the left to the right eyes, keratometric cylinder, pupillary diameter, predicted refraction, or intervals between surgery and examination between the two groups. However, the mean age of the in-the-bag scleral suturing group was significantly less than that of the out-of-the-bag suturing group $(P=0.0019)$.

The mean tilt angle and decentration length of the IOL of the in-the-bag scleral suturing group was significantly less than those of the out-of-the-bag suturing group ( $P=0.0003$ in tilt and $P=0.0391$ in decentration) (Figure 2). However, no significant difference was found in the mean anterior chamber depth between the two
Table 1 Patient characteristics of the in-the-bag scleral suturing and out-of-the-bag scleral suturing groups

\begin{tabular}{lccc}
\hline Characteristic & $\begin{array}{c}\text { In-the-bag } \\
\text { scleral } \\
\text { suturing } \\
\text { group }\end{array}$ & $\begin{array}{c}\text { Out-of-the-bag } \\
\text { scleral } \\
\text { suturing } \\
\text { group }\end{array}$ & P-value \\
& $59.1 \pm 13.6$ & $69.2 \pm 13.4$ & $0.0019^{\mathrm{a}}$ \\
\hline Age (years) & $10 / 20$ & $15 / 23$ & 0.6021 \\
Gender (M/F) & $12 / 18$ & $16 / 22$ & 0.8609 \\
Left/right & $1.50 \pm 0.98$ & $1.94 \pm 1.23$ & 0.1628 \\
Keratometric cylinder (D) & & & \\
& & & \\
Pupillary diameter (mm) & $3.70 \pm 1.11$ & $3.49 \pm 0.68$ & 0.6803 \\
$\quad$ Photopic & $4.29 \pm 1.03$ & $4.21 \pm 0.78$ & 0.9031 \\
$\quad$ Mesopic & & & \\
& & & \\
Predicted refraction (D) & $-0.43 \pm 0.52$ & $-0.52 \pm 0.41$ & 0.1083 \\
Interval (days) & $389 \pm 464$ & $442 \pm 422$ & 0.1555 \\
\hline
\end{tabular}

Abbreviations: $\mathrm{D}$, diopter; F, female; $\mathrm{M}$, male.

aStatistically significant difference.

${ }^{b}$ Elapsed time between surgery and examination.

groups $(3.60 \pm 0.35 \mathrm{~mm}$ for the in-the-bag suturing group and $3.57 \pm 0.41 \mathrm{~mm}$ for the out-of-the-bag suturing group; $P=0.7858)$. Furthermore, the number of eyes that developed a marked tilt of more than 10 degree was significantly less in the in-the-bag scleral suturing group than in the out-of-the-bag suturing group $(P=0.0074)$, although the number of eyes that showed a decentration of greater than $1.0 \mathrm{~mm}$ was not significantly different.

The mean diopter (D) of spherical power of the in-thebag scleral suturing group was significantly less myopic than that of the out-of-the-bag scleral suturing group $(-0.52 \pm 1.38 \mathrm{D}$ for the in-the-bag suturing group and $-1.50 \pm 1.72 \mathrm{D}$ for the out-of-the-bag suturing group; $P=0.0008)$, although cylindrical power was not different $(1.98 \pm 1.05 \mathrm{D}$ for the in-the-bag suturing group and $2.33 \pm 1.44 \mathrm{D}$ for the out-of-the-bag suturing group; $P=0.5699)$. Subsequently, the manifest spherical equivalent of the in-the-bag suturing group was significantly less myopic than that of the out-of-the-bag suturing group ( $P=0.0006)$ (Figure 3$)$. Furthermore, as the predicted refraction of the two groups was similar, the mean absolute value of prediction error was less for the in-the-bag suturing group than that for the out-ofthe-bag suturing group $(P=0.0034)$.

Mean uncorrected decimal visual acuity was 0.37 in the in-the-bag group and 0.29 in the out-of-the-bag group, whereas mean spectacle-corrected visual acuity was 0.71 in the in-the-bag suturing group and 0.78 in the out-of-the-bag group; neither difference was statistically significant. The reasons for worse corrected visual acuity (worse than 0.5) in the in-the-bag scleral suturing group were advanced glaucoma in 5 eyes, macular degeneration in 2 eyes, and retinopathy of prematurity in 1 eye, whereas those in the out-of-the-bag group were 
Tilt

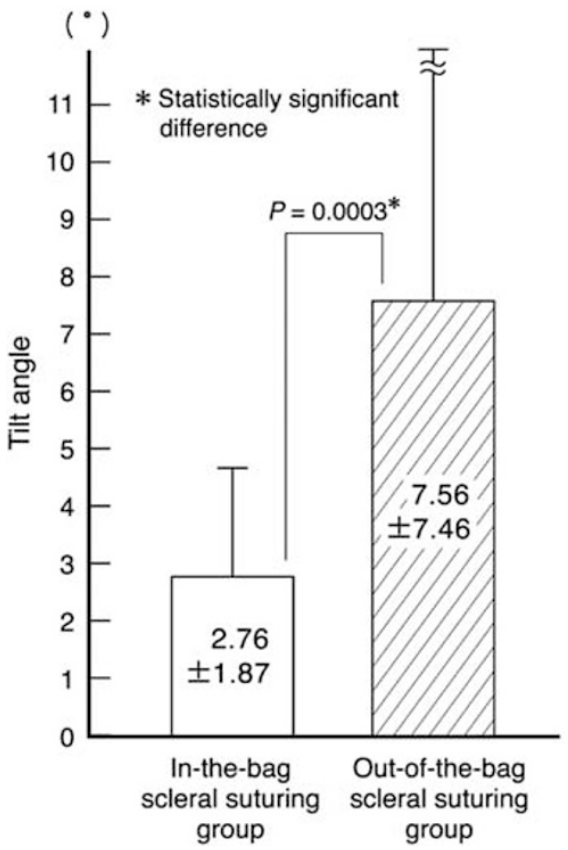

Decentration

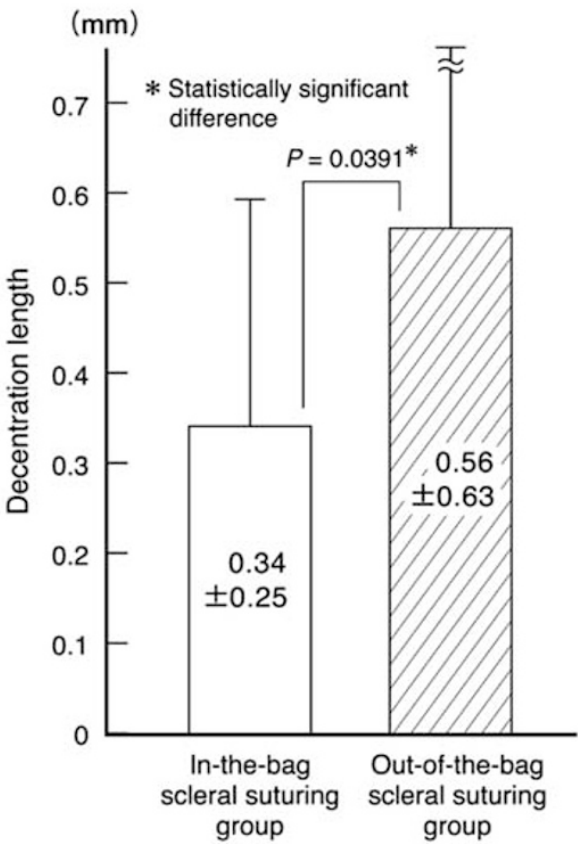

Figure 2 Comparison of mean $( \pm S D$ ) tilt angle and decentration length of IOLs between the in-the-bag scleral suturing and out-ofthe-bag scleral suturing groups. The mean tilt angle and decentration length of the IOL for the in-the-bag scleral suturing group are significantly less than those for the out-of-the-bag suturing group.

Spherical equivalent value

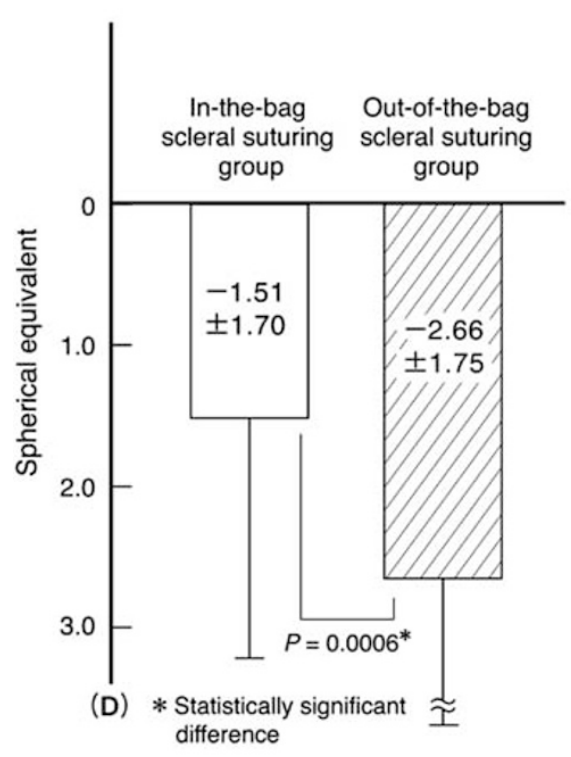

Prediction error

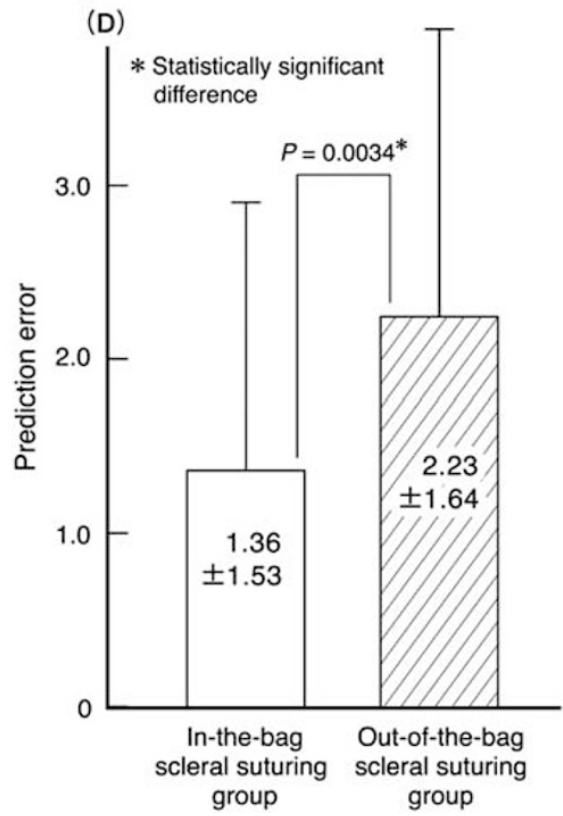

Figure 3 Comparison of mean $( \pm S D)$ manifest spherical equivalent value and the absolute value of prediction error between the in-the-bag scleral suturing and out-of-the-bag scleral suturing groups. The mean manifest spherical equivalent value and the absolute value of prediction error for the in-the-bag scleral suturing group are significantly less than are those for the out-of-the-bag scleral suturing group.

advanced glaucoma in 3 eyes, retinitis pigmentosa in 2 eyes, and closed macular hole after viterectomy in 1 eye.
In either the in-the-bag or the out-of-the-bag group, there was no significant difference between eyes that received the single-piece PMMA IOL (CZ70BD) and 
Table 2 Incidence of intra-operative or postoperative complications of the in-the-bag scleral suturing and out-of-the-bag scleral suturing groups

\begin{tabular}{lccc}
\hline Complications & $\begin{array}{c}\text { In-the-bag } \\
\text { scleral } \\
\text { suturing } \\
\text { group }\end{array}$ & $\begin{array}{c}\text { Out-of-the-bag } \\
\text { scleral } \\
\text { suturing } \\
\text { group }\end{array}$ & P-value \\
\hline Vitreous loss & $6(20.0 \%)$ & $24(63.2 \%)$ & $0.0004^{\mathrm{a}}$ \\
Temporary increase in IOP & 0 & $4(10.5 \%)$ & 0.1243 \\
Glaucoma escalation & 0 & $3(7.9 \%)$ & 0.2493 \\
Pupil capture & 0 & $2(5.3 \%)$ & 0.4996 \\
Vitreous haemorrhage & $1(3.3 \%)$ & 0 & 0.4412 \\
PCO & $2(6.7 \%)$ & 0 & 0.1910 \\
Cystoid macular edema & 0 & $1(2.6 \%)$ & $>0.9999$ \\
Retinal detachment & 0 & $1(2.6 \%)$ & $>0.9999$ \\
Endophthalmitis & 0 & 0 & - \\
\hline
\end{tabular}

Abbreviations: IOP, intraocular pressure; PCO, posterior capsule opacification.

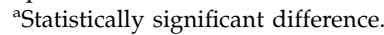

those that received the multi-piece acrylic IOL (VA65BB) with regard to decentration length and tilt angle, anterior chamber depth, spherical equivalent, or prediction error. Furthermore, in the out-of-the-bag group, there was no significant difference between eyes that underwent planned intracapsular cataract extraction and eyes that underwent IOL exchange or eventful phacoemulsification surgery with regard to mean decentration length and tilt angle, anterior chamber depth, manifest spherical equivalent value, or prediction error.

The incidence of operative complications in the two groups is shown in Table 2. The number of eyes that showed vitreous prolapse was significantly lower for the in-the-bag suturing group than for the out-of-the-bag suturing group $(P=0.0005)$. The number of eyes that showed a transient increase in IOP and glaucoma escalation tended to be lower in the in-the-bag suturing group than in the out-of-the-bag suturing group, but this difference was not significant. In addition, pupil capture, cystoid macular edema, and retinal detachment did not occur at all in the in-the-bag suturing group, whereas these did occur in four eyes in the out-of-the-bag suturing group. However, a severe posterior capsule opacification that required an Nd:YAG laser capsulotomy occurred in two eyes $(6.7 \%)$ in the in-the-bag suturing group; the incidence between the groups was not significantly different $(P=0.1910)$.

\section{Discussion}

Our study has shown that the degree of tilt and decentration of the IOL after in-the-bag scleral suturing is significantly less than that after out-of-the-bag suturing, whereas anterior chamber depth is similar. In fact, none of the eyes that underwent in-the-bag suturing showed a tilt of more than 10 degrees or a decentration of more than $1.0 \mathrm{~mm}$. These results suggest that IOL displacement may be prevented by scleral suture fixation of the IOL within the capsular bag-even in eyes with dehiscent zonules.

The manifest spherical equivalent value, specifically spherical power, with in-the-bag scleral suturing of the IOL was significantly less myopic than that with out-ofthe-bag scleral suturing, and as targeted refraction was similar, the absolute value of prediction error was also less. It has been shown that tilt and decentration of the IOL, as well as axial shift, cause the refractive error, particularly myopic shift. ${ }^{31-33}$ As anterior chamber depth was similar between the two groups in this study, less IOL tilt and decentration with in-the-bag scleral suturing might decrease the refractive error as well as the error in prediction.

As for operative complications, the incidence of vitreous loss was significantly less with in-the-bag scleral suturing than with out-of-the-bag scleral suturing. In addition, the amount of prolapsed vitreous was less with in-the-bag scleral suturing than with out-of-the-bag suturing, and, thus, the surgical procedure to remove the vitreous was easier. Furthermore, cystoid macular edema and retinal detachment, presumably related to vitreous loss, did not occur after in-the-bag scleral suturing, whereas these complications occurred in two eyes after out-of-the-bag scleral suturing. These results suggest that vitreous prolapse is prevented by the presence of the lens capsule with in-the-bag suturing, and retinal complications may decrease.

Furthermore, the incidence of a transient increase in IOP and glaucoma escalation tended to be higher with out-of-the-bag scleral suturing of the IOL than with in-the-bag suturing; indeed, transient elevation of the IOP and glaucoma escalation did not occur in any eye after in-the-bag suturing. In addition, pupil capture did not occur in any eye after in-the-bag scleral suturing, whereas repeated pupil capture did occur in two eyes after out-of-the-bag suturing. These results suggest that the lens capsule that encapsulates the IOL may reduce damage to the iris and ciliary body, which subsequently leads to less increase in IOP caused by chronic inflammation and iris pigment dispersion.

Conventionally, intracapsular cataract extraction had been performed for eyes with severe zonular dehiscence or lens subluxation. Capsule stabilization devices have facilitated the use of phacoemulsification for such eyes, while preserving integrity of the capsular bag. ${ }^{24-28}$ Phacoemulsification and scleral suturing of foldable IOLs $^{29}$ decreases wound size to approximately $4 \mathrm{~mm}$ in length. Furthermore, a PC-IOL can be sutured to the sclera or iris within the preserved capsular bag, which 
may lead to less IOL displacement. Despite these possible advantages, there has been no study focused on the suture fixation of a PC-IOL within the capsular bag.

There are four options for IOL implantation in aphakic eyes with inadequate capsular support: ${ }^{1}$ (1) An openloop AC-IOL, ${ }^{2-4}$ (2) a scleral-sutured PC-IOL, ${ }^{5-7}$ (3) an iris-sutured PC-IOL, ${ }^{8-10}$ and (4) a scleral-sutured modified capsular tension ring. ${ }^{11-14}$ AC-IOLs have been improved from a closed-loop design to an open-loop design, and the open-loop AC-IOLs have been shown to be less traumatic to corneal endothelial cells than are closed-loop AC-IOLs. ${ }^{3,4}$ However, studies have shown that corneal edema with open-loop AC-IOLs occurs more frequently than with scleral-sutured or iris-sutured PC-IOLs, and that glaucoma escalation occurs at an incidence of between 1.3 and $15 \% .^{1-3}$ Thus, such complications to the angle may be unavoidable with the AC-IOL. On the other hand, iris suture fixation of the posterior chamber IOLs has similar advantages to scleral suture fixation, although iris suture fixation is technically more difficult to perform than scleral suturing. In addition, iris suture fixation has potential risks related to iris chafing, which may lead to iris pigment dispersion, inflammation, and cystoid macular edema. ${ }^{1,8-10}$ Furthermore, the standard modified capsular tension ring is sutured to the sclera at one site. However, there is only one case report that showed decentration and tilt of the IOL. ${ }^{23}$ Accordingly, there is no conclusive evidence as to whether or not iris suture fixation of the IOL or the scleral-sutured capsular tension ring is comparable to scleral fixation of the IOL.

Scleral suture fixation of PC-IOLs has potential risks that are characteristic of this technique. Tilt and decentration of the IOL, as well as axial shift of the IOL owing to inadequate haptic position, are considered to be major risks of scleral suture fixation. ${ }^{18-22}$ However, the tilt and decentration of the IOL after in-the-bag scleral suturing noted in this study was slight, and the degree was similar to that after ordinary in-the-bag implantation of the IOL. ${ }^{22,34}$ In addition, although vitreous haemorrhage, retinal detachment, and endophthalmitis are potential risks that may occur during or after scleral suturing, ${ }^{18,20-22,35}$ these complications were rare in this series.

A limitation exists in this study. The techniques of cataract extraction were different between the in-the-bag suturing and out-of-the-bag suturing groups. The out-ofthe-bag suturing group included eyes that underwent large incision surgery, such as intracapsular cataract extraction. However, there were no significant differences in outcomes between eyes that underwent intracapsular cataract extraction and those that underwent the other techniques. Furthermore, the gist of this study was to verify the possible advantages of in-the-bag scleral fixation, when this technique can be safely employed.

In conclusion, the tilt and decentration of the IOL with in-the-bag scleral suturing was significantly less than that with out-of-the-bag scleral suturing, which may lead to less myopic shift of the spherical equivalent value as well as less error in prediction. ${ }^{31-33}$ Furthermore, vitreous prolapse was also less with in-the-bag scleral suturing than with out-of-the-bag suturing. Accordingly, although the technique of in-the-bag scleral suturing is difficult, we believe that surgeons should try to maintain the lens capsule and suture the IOL within the capsular bag in eyes with severe zonular dehiscence specifically for young patients. However, it is not yet clear which is the best option, scleral suture fixation of the IOL, iris suture fixation, or scleral fixation of the capsular tension ring, and further study is called for to compare the outcomes between the three options.

\section{Summary}

What was known before

- The degree of decentration or tilt of the IOL after scleral suture fixation outside the lens capsule (out-of-the-bag scleral suturing of the IOL) is significantly greater than that after either ordinary in-the-bag or out-of-the-bag implantation of the IOL, and this change in the positioning of the IOL can lead to myopic shit of the spherical equivalent value and error in prediction.

\section{What this study add}

- The decentration and tilt of the IOL after scleral suture fixation within the capsular bag (in-the-bag scleral suturing of the IOL) were significantly less than that after out-of-the-bag scleral suturing, which may lead to less myopic shift of the spherical equivalent value as well as less error in prediction.

\section{Conflict of interest}

The authors declare no conflict of interest.

\section{References}

1 Wagoner MD, Cox TA, Ariyasu RG, Jacobs DS, Karp CL. Intraocular lens implantation in the absence of capsular support. Ophthalmology 2003; 110: 840-859.

2 Hennig A, Evans JR, Pradhan D, Johnson GJ, Pokhrel RP, Gregson RMC et al. Randomised controlled trial of anteriorchamber intraocular lenses. Lancet 1997; 349: 1129-1133.

3 Bergman M, Laatikainen L. Long-term evaluation of primary anterior chamber intraocular lens implantation in complicated cataract surgery. Int Ophthalmol 1996-1997; 20: 295-299.

4 Bellucci R, Pucci V, Morselli S, Bonomi L. Secondary implantation of angle-supported anterior chamber and scleral-fixated posterior chamber intraocular lenses. J Cataract Refract Surg 1996; 22: 247-252. 
5 Malbran ES, Malbran Jr E, Negri I. Lens guide suture for transport and fixation in secondary IOL implantation after intracapsular extraction. Int Ophthalmol 1986; 9: 151-160.

6 Stark WJ, Gottsch JD, Goodman DF, Goodman GL, Pratzer K. Posterior chamber intraocular lens implantation in the absence of capsular support. Arch Ophthalmol 1989; 107: 1078-1083.

7 Mittelviefhaus $\mathrm{H}$, Wiek J. A refined technique of transscleral suture fixation of posterior chamber lenses developed for cases of complicated cataract surgery with vitreous loss. Ophthalmic Surg 1993; 24: 698-701.

8 Navia-Aray EA. Suturing a posterior chamber intraocular lens to the iris through limbal incisions: results in 30 eyes. J Refract Corneal Surg 1994; 10: 565-570.

9 Condon GP. Simplified small-incision peripheral iris fixation of an AcrySof intraocular lens in the absence of capsule support. J Cataract Refract Surg 2003; 29: 1663-1667.

10 Condon GP, Masket S, Kranemann C, Crandall AS, Ahmed IIK. Small-incision iris fixation of foldable intraocular lenses in the absence of capsule support. Ophthalmology 2007; 114: 1311-1318.

11 Cionni RJ, Osher RH. Management of profound zonular dialysis or weakness with a new endocapsular ring designed for scleral fixation. J Cataract Refract Surg 1998; 24: 1299-1306.

12 Cionni RJ, Osher RH, Marques DMV, Marques FF, Snyder ME, Shapiro S. Modified capsular tension ring for patients with congenital loss of zonular support. J Cataract Refract Surg 2003; 29: 1668-1673.

13 Ahmed IIK, Crandall AS. Ab externo scleral fixation of the Cionni modified capsular tension ring. J Cataract Refract Surg 2001; 27: 977-981.

14 Moreno-Montañés J, Sainz C, Maldonado MJ. Intraoperative and postoperative complications of Cionni endocapsular ring implantation. J Cataract Refract Surg 2003; 29: 492-497.

15 Pavlin CJ, Rootman D, Arshinoff S, Harasiewicz K, Foster FS. Determination of haptic position of transsclerally fixated posterior chamber intraocular lenses by ultrasound biomicroscopy. J Cataract Refract Surg 1993; 19: 573-577.

16 Kamal AM, Hanafy M, Ehsan A, Tomerak RH. Ultrasound biomicroscopy comparison of $a b$ interno and ab externo scleral fixation of posterior chamber intraocular lenses. J Cataract Refract Surg 2009; 35: 881-884.

17 Mura JJ, Pavlin CJ, Condon GP, Belovay GW, Kranemann $\mathrm{CF}$, Ishikawa $\mathrm{H}$ et al. Ultrasound biomicroscopic analysis of iris-sutured foldable posterior chamber intraocular lenses. Am J Ophthalmol 2010; 149: 245-252.

18 Solomon K, Gussler JR, Gussler C, Van Meter WS. Incidence and management of complications of transsclerally sutured posterior chamber lenses. J Cataract Refract Surg 1993; 19: 488-493.

19 Durak A, Öner HF, Koçak N, Kaynak S. Tilt and decentration after primary and secondary transsclerally sutured posterior chamber intraocular lens implantation. J Cataract Refract Surg 2001; 27: 227-232.

20 Grigorian R, Chang J, Zarbin M, Del Priore L. A new technique for suture fixation of posterior chamber intraocular lenses that eliminates intraocular knots. Ophthalmology 2003; 110: 1349-1356.
21 Mimura T, Amano S, Sugiura T, Funatsu H, Yamagami S, Oshika T et al. 10-year follow-up study of secondary transscleral ciliary sulcus fixated posterior chamber intraocular lenses. Am J Ophthalmol 2003; 136: 931-933.

22 Hayashi K, Hayashi H, Nakao F, Hayashi F. Intraocular lens tilt and decentration, anterior chamber depth, and refractive error after trans-scleral suture fixation surgery. Ophthalmology 1999; 106: 878-882.

23 Kohnen T, Baumeister M, Bühren J. Scheimpflug imaging of bilateral foldable in-the-bag intraocular lens implantation assisted by a scleral-sutured capsular tension ring in Marfan's syndrome. J Cataract Refract Surg 2003; 29: 598-602.

24 Novák J. Flexible iris hooks for phacoemulsification. J Cataract Refract Surg 1997; 23: 828-831.

25 Santoro S, Sannace C, Cascella MC, Lavermicocca N. Subluxated lens: phacoemulsification with iris hooks. J Cataract Refract Surg 2003; 29: 2269-2273.

26 Nishimura E, Yaguchi S, Nishihara H, Ayaki M, Kozawa T. Capsular stabilization device to preserve lens capsule integrity during phacoemulsification with a weak zonule. J Cataract Refract Surg 2006; 32: 392-395.

27 Menapace R, Findl O, Georgopoulos M, Rainer G, Vass C, Schmetterer $\mathrm{K}$. The capsular tension ring: designs, applications, and techniques. J Cataract Refract Surg 2000; 26: 898-912.

28 Jacob S, Agarwal A, Agarwal A, Agarwal S, Patel N, Lal V. Efficacy of a capsular tension ring for phacoemulsification in eyes with zonular dialysis. J Cataract Refract Surg 2003; 29: 315-321.

29 Yaguchi S, Yaguchi S, Noda Y, Taguchi Y, Negishi K, Tsubota K. Foldable acrylic intraocular lens with distended haptics for transscleral fixation. J Catarct Refract Surg 2009; 35: 2047-2050.

30 Gimbel H, Condon G, Kohnen T, Olson R, Halkiadakis I. Late 'in-the-bag' intraocular lens dislocation: prevention and management. J Cataract Refract Surg 2005; 31: 2193-2204.

31 Erickson P. Effects of intraocular lens position errors on postoperative refractive error. J Cataract Refract Surg 1990; 16: 305-311.

32 Korynta J, Bok J, Cendelin J. Changes in refraction induced by change in intraocular lens position. J Refract Corneal Surg 1994; 10: 556-564.

33 Korynta J, Bok J, Cendelin J, Michalova K. Computer modeling of visual impairment caused by intraocular lens misalignment. J Cataract Refract Surg 1999; 25: 100-105.

34 Hayashi K, Yoshida M, Nakao F, Hayashi H. Prevention of anterior capsule contraction by anterior capsule relaxing incisions with neodymium:yttrium-aluminum-garnet laser. Am J Ophthalmol 2008; 146: 23-30.

35 Schechter RJ. Suture-wick endophthalmitis with sutured posterior chamber intraocular lenses. J Cataract Refract Surg 1990; 16: 755-756. visit http://creativecommons.org/licenses/by-nc-sa/3.0/ 